\title{
Indução de resistência à Macrophomina phaseolina em soja tratada com extrato de alecrim
}

\author{
Eloisa Lorenzetti ${ }^{1,3}$; José Renato Stangarlin ${ }^{1}$; Odair José Kuhn ${ }^{1}$; Roberto Luis Portz ${ }^{2}$
}

\begin{abstract}
${ }^{1}$ Universidade Estadual do Oeste do Paraná - UNIOESTE, Rua Pernambuco 1777, CP 91, CEP 85960-000, Marechal Cândido Rondon - Paraná Brasil. jose.stangarlin@unioeste.br; ojkuhn@gmail.com. ${ }^{2}$ Universidade Federal do Paraná - UFPR, Rua Pioneiro 2153, CEP 85950-000, Palotina - Paraná - Brasil. roberto.portz@ufpr.br. ${ }^{3}$ Bolsista CAPES
\end{abstract}

Autor para correspondência: Eloisa Lorenzetti (eloisa-lorenzetti@hotmail.com)

Data de chegada: 10/03/2017. Aceito para publicação em: 15/09/2017.

$10.1590 / 0100-5405 / 176895$

\section{RESUMO}

Lorenzetti, E.; Stangarlin, J.R.; Kuhn, O.J.; Roberto Luis Portz, R.L. Indução de resistência à Macrophomina phaseolina em soja tratada com extrato de alecrim. Summa Phytopathologica, v.44, n.1, p. 45-50, 2018.

Extratos vegetais podem induzir mecanismos de resistência de plantas em função da presença de compostos com características eliciadoras. O objetivo deste estudo foi avaliar o efeito do extrato bruto de alecrim nas concentrações $0 \% ; 1 \% ; 2,5 \%$ e $5 \%$ sobre a atividade de peroxidase, polifenoloxidase e fenilalanina amônia-liase (FAL) em soja inoculada com Macrophomina phaseolina. Foram retiradas amostras nos tempos 0, $36,72,120,168,216$ e $264 \mathrm{~h}$ após o tratamento. Nas amostras retiradas do colo das plantas, para peroxidase, as concentrações mais elevadas do extrato proporcionaram dois picos de indução. Houve constante incremento na atividade de polifenoloxidase desde 36 até $120 \mathrm{~h}$ após o tratamento para a concentração 5\%. Para FAL apenas a concentração $5 \%$ promoveu incremento $83 \%$ e $130 \%$ maior nos tempos 168 e $216 \mathrm{~h}$ após o tratamento, respectivamente. Para as atividades na raiz, peroxidase novamente apresentou dois picos de incremento para concentração $5 \%$, a polifenoloxidase foi $426 \%$ maior na concentração $5 \%$ às $216 \mathrm{~h}$ após o tratamento e a atividade de FAL apresentou incremento de $340 \%$ no tempo 216 h após o tratamento com $5 \%$ do extrato. Estes resultados indicam o potencial do extrato de alecrim em induzir a atividade de enzimas de defesa em colo e raiz de soja.

Palavras-chave: Fenilalanina amônia-liase. Indução de resistência. Peroxidase. Polifenoloxidase.

\section{ABSTRACT}

Lorenzetti, E.; Stangarlin, J.R.; Kuhn, O.J.; Roberto Luis Portz, R.L. Induction of resistance to Macrophomina phaseolina in soyben treated with rosemary extract. Summa Phytopathologica, v.44, n.1, p. 45-50, 2018.

Plant extracts may induce resistance mechanisms in plants due to the presence of compounds with eliciting characteristics. The aim of this study was to evaluate the effect of rosemary crude extract at the concentrations $0 \% ; 1 \% ; 2.5 \%$ and $5 \%$ on the activity of peroxidase, polyphenol oxidase and phenylalanine ammonia-lyase (PAL) in soybean plants inoculated with Macrophomina phaseolina. Samples were collected at 0, 36, 72, 120, 168, 216 and 264 hours after treatment. Considering the samples collected at the collar region of plants, for peroxidase, the highest concentrations of the extract provided two induction peaks. There was a constant increase in polyphenol oxidase activity from 36 to 120 hours after treatment at 5\% concentration. For PAL, only the concentration of $5 \%$ led to increases $83 \%$ to $130 \%$ higher at 168 and 216 hours after treatment, respectively. For the activities in the root, peroxidase again showed two increment peaks at $5 \%$ concentration; polyphenol oxidase was $426 \%$ higher at $5 \%$ concentration at 216 hours after treatment and PAL activity showed an increase of $340 \%$ at 216 hours after treatment with $5 \%$ extract. These results indicate the potential of rosemary extract to induce the activity of defense enzymes in the collar region and in the root of soybean plants.

Keywords: Phenylalanine ammonia-lyase, resistance induction, peroxidase, polyphenol oxidase.

Dentre as doenças da cultura da soja, a podridão cinzenta da haste ou podridão carvão, causada pelo fungo Macrophomina phaseolina (Tassi) Goid (1947), tem acarretando expressivas perdas econômicas. Esta doença é considerada de difícil manejo inexistindo controle químico e cultivares resistentes (18), e, por este ser polífago, a rotação de culturas é ineficiência (2). Assim, justifica-se a utilização de métodos alternativos de controle para essa doença, como a indução de resistência.

A indução de resistência é a ativação dos mecanismos latentes de defesa das plantas contra patógenos, o que pode ocorrer pelo tratamento destas com moléculas eliciadoras de origem biótica ou abiótica. Dentre os mecanismos de defesa da planta que podem ser ativados destacamos as enzimas, como a peroxidase, envolvida nos processos de lignificação celular, polifenoloxidase que transforma fenóis em quinonas tóxicas aos microrganismos, e fenilalanina amônia-liase, enzima precursora da síntese dos fenilpropanóides envolvidos na defesa vegetal (24).

Dentre os eliciadores utilizados na indução de resistência como prática de manejo de doenças, estão os extratos e óleos essenciais de plantas medicinais, com eficácia comprovada para inúmeros patossistemas (25).

O alecrim (Rosmarinus officinalis L.) é uma planta medicinal da Família Lamiaceae e apresenta compostos como pineno, canfeno, cineol, borneol, acetato de bornila, cânfora, diterpenos, ácidos orgânicos saponina, traços de alcaloides, taninos e ácido rosmarínico (26). O potencial de alecrim para controle de fitopatógenos tem sido verificado em diversos patossistemas, como Pseudocercospora vitis e Plasmopara viticola em videira (14), Alternaria solani em soja (17), Cladosporium fulvum em tomateiro (11), Ralstonia solanacearum em pimentão (15), Meloidogyne javanica (16) e M. incognita (19) em soja. 
O objetivo deste trabalho foi avaliar o efeito de concentrações do extrato de alecrim sobre a atividade de peroxidase, polifenoloxidase e fenilalanina amônia-liase em soja inoculada com Macrophomina phaseolina.

\section{MATERIAL E MÉTODOS}

Primeiro, para obtenção do extrato a ser testado como indutor, $50 \mathrm{~g}$ de folhas frescas de alecrim em $450 \mathrm{~mL}$ de água destilada foram trituradas em liquidificador durante 2 minutos, sendo a mistura obtida filtrada através de peneiras de 48, 200 e 400 mesh sobrepostas. O filtrado final obtido foi considerado como extrato bruto de alecrim a $10 \%$ sendo este posteriormente diluído a $1 \%, 2,5 \%$ e $5 \%$ em água destilada.

Sementes de soja da cultivar 6563 PSF IPRO foram semeadas em vasos plásticos de $2 \mathrm{~L}$ contendo uma mistura solo, areia e matéria orgânica na proporção de 2:1:1 (v/v/v). Essas sementes foram semeadas a aproximadamente $2,5 \mathrm{~cm}$ de profundidade e, após emergirem realizouse o raleio, mantendo três plantas por vaso.

Quando as plantas apresentaram o primeiro trifólio totalmente expandido (estádio fenológico V2), foi realizado o tratamento das plantas com o extrato de alecrim na região do colo (região entre o solo e a inserção dos cotilédones) e no solo, utilizando-se borrifadores com o extrato nas concentrações $0 \% ; 1 \% ; 2,5 \%$ e $5 \%$. Foram pulverizados aproximadamente $1 \mathrm{~mL}$ no colo e $2 \mathrm{~mL}$ no solo. Não houve ferimento na região do colo e nas raízes. Três dias (72 horas) após o tratamento, foi realizada a inoculação do fungo $M$. phaseolina, a partir de uma colônia do fungo com 14 dias de cultivo em placa de Petri de onde foram retirados quatro discos de $1 \mathrm{~cm}$ de diâmetro que foram colocados em contato com o colo e às raízes próximas ao colo sem que fosse realizado algum tipo de ferimento nos locais.

A coleta das amostras do colo das plantas de soja foi realizada cortando-se o caule $2 \mathrm{~cm}$ acima do solo e $1 \mathrm{~cm}$ abaixo do solo, totalizando uma amostra de $3 \mathrm{~cm}$ do caule constituinte do colo. A coleta das amostras das raízes foi realizada cortando-se os $2 \mathrm{~cm}$ iniciais das raízes a partir do caule. Este processo foi realizado a 0, 36, 72, 120, 168,216 e 264 horas após os tratamentos tanto para o colo quanto para a raiz. Essas amostras foram lavadas em água corrente e imediatamente acondicionada em envelopes de papel alumínio e congeladas a $-20^{\circ} \mathrm{C}$.

Tanto as amostras de colo quanto as de raízes foram trituradas em $4 \mathrm{~mL}$ de tampão fosfato de sódio $0,01 \mathrm{M}(\mathrm{pH} 6,0)$ em almofariz de porcelana. O homogeneizado foi centrifugado a $6.000 \mathrm{~g}$ durante $20 \mathrm{~min}$ a $4{ }^{\circ} \mathrm{C}$. O sobrenadante obtido, considerado como a fração contendo as proteínas solúveis, o qual foi armazenado em micro tubos a $-20{ }^{\circ} \mathrm{C}$ para posteriores análises bioquímicas.

A atividade da peroxidase foi determinada a $30{ }^{\circ} \mathrm{C}$ por método espectrofotométrico direto utilizando guaiacol (10). Para determinação da atividade das polifenoloxidases foi utilizado catecol conforme metodologia de Duangmal \& Apenten (8). A atividade da fenilalanina amônia-liase foi determinada através da quantificação colorimétrica do ácido trans-cinâmico liberado do substrato fenilalanina segundo a metodologia descrita por Umesha (27). O conteúdo proteico foi determinado pelo método de Bradford (5).

O delineamento experimental foi blocos casualizados com quatro tratamentos constituídos pelas diluições do extrato bruto de $R$. officinalis $0 \% ; 1 \% ; 2,5 \%$ e $5 \%$ com cinco repetições. Cada repetição foi representada por um vaso com três plantas. As médias dos tratamentos foram comparadas pelo teste Dunnett, a 5\% de probabilidade por meio do software livre Genes (7).

\section{RESULTADOS E DISCUSSÃO}

As plantas de soja tratadas com extrato de alecrim, às concentrações de $1 \%, 2,5 \%$ e $5 \%$ incrementaram a atividade de peroxidase 36 horas após o tratamento. Nos tempos de 72 e 120 horas os tratamentos não diferiram estatisticamente (Figura 1A).

Porém, para as concentrações $2,5 \%$ e $5 \%$ houve um incremento acentuado 168 horas após o tratamento, incremento este que foi em média 75,57\% maior que o controle. Para essas dois concentrações do extrato, verificaram-se dois de indução.

O primeiro ocorreu 36 horas após o tratamento (Figura 1A) podendo estar relacionado com o próprio efeito indutor do tratamento ou até mesmo a um efeito priming, pois não havendo a inoculação verificase que a atividade tendeu a voltar ao normal. Após a inoculação do fungo no tempo 72 horas após o tratamento, verificou-se a ocorrência do segundo pico de atividade, momento em que estaria ocorrendo a tentativa de infecção pelo patógeno. Este segundo pico pode estar relacionado não apenas ao processo infeccioso, mas principalmente ao processo de indução da resistência, já que a atividade foi verificada apenas para os tratamentos $2,5 \%$ e $5 \%$, e não para a concentração $1 \%$, provavelmente insuficiente, e nem para a concentração $0 \%$, onde as plantas também passaram pelo processo de inoculação.

Dessa forma, com relação à peroxidase, para as duas concentrações mais altas do extrato de alecrim utilizadas, o processo parece ocorrer em dois picos, sendo um pico inicial que pode caracterizar um priming seguido de um pico mais acentuado que se manifesta após o início do processo infeccioso. A ocorrência de um segundo pico de mecanismos de defesa ou compostos de sinalização após o estabelecimento efetivo do processo infeccioso, é algo que pode ocorer, como é caso do etileno (20). Este sinalizador pode apresentar dois picos de produção, ambos após o início do processo infeccioso, mas sendo o segundo maior quando da colonização dos tecidos do hospedeiro pelo patógeno, momento em que vários mecanismos de defesa se expressam de maneira mais acentuada (20).

O tratamento com extrato de alecrim $1 \%$ demonstrou apenas um pico inicial no tempo 36 horas, com posterior atividade constante, semelhante ao controle. Isso pode ter ocorrido devido a concentração do extrato de alecrim estar muito baixa e, portanto, não induziu a resistência da planta a ponto de elevar a atividade da enzima peroxidase após a inoculação do patógeno.

Segundo Viecelli et al. (28), a alteração na atividade de peroxidase é correlacionada a suscetibilidade ou resposta de resistência em diversos patossistemas. Esta enzima, segundo Resende et al. (21), é responsável por catalisar a oxidação de álcoois fenólicos à lignina, fazendo com que ocorram mudanças na parede celular e proporcionando mais resistência contra as toxinas que são liberadas pelos patógenos. Boava et al. (3) concluíram que a atividade de peroxidases resulta de uma alteração no metabolismo normal da planta e, portanto, promove mudanças até mesmo em outras enzimas que possuem rota metabólica em comum. Mudanças da atividade de peroxidases podem ser indício de indução de resistência, já que as enzimas agem de forma preventiva, buscando impedir que o patógeno penetre a parede celular (24). Segundo Formentini (9), uma atividade mesmo que baixa ou uma atividade mais expressiva inicialmente, podem ter relação com a pré-disposição a resistência e, portanto, apresentarem uma maior expressão quando o patógeno inicia o processo infeccioso.

Para a polifenoloxidase no colo (Figura 1B), a concentração 5\% do extrato de alecrim foi a única que promoveu incremento na atividade às 36 horas após o tratamento, bem como as 72 e 120 horas após o tratamento. Verifica-se que houve um incremento constante na atividade 

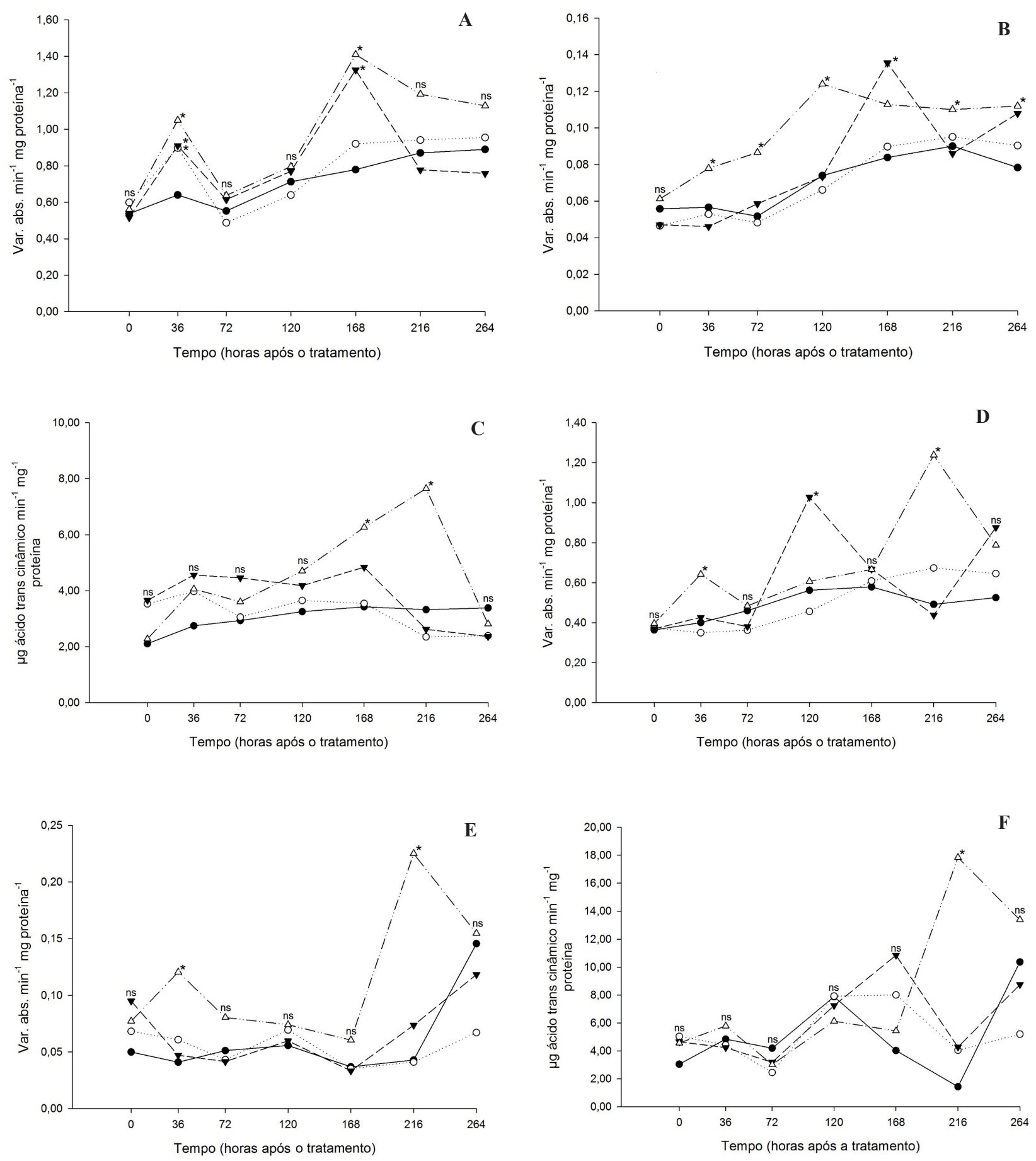

Figura 1 - Atividades de peroxidase (A) e (D), de polifenoloxidase (B) e (E) e de fenilalanina amônia-liase (C) e (F) em colo (A, B e C) e raiz (D, E e D) de soja, respectivamente, cujas hastes e solo do vaso de cultivo foram tratados com extrato de alecrim em concentrações de 1\% (…..........),

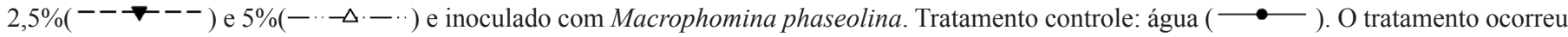
no tempo zero e a inoculação 72 horas após o mesmo. *: indica diferença significativa, dentro de cada tempo de amostragem, pelo teste Dunnett $(\mathrm{P} \leq 0,05)$ quando comparada ao controle água. ${ }^{\text {ns. }}$ não significativo.

da enzima polifenoloxidase desde 36 até 120 horas após o tratamento. Observa-se uma atividade constante nos tempos 216 a 264 horas após o tratamento. Para a concentração $2,5 \%$ do extrato de alecrim, houve diferença significativa no tempo 168 horas após o tratamento com aumento na atividade da enzima $61,69 \%$ maior que o controle. Este incremento pode estar relacionado ao próprio processo infeccioso diferentemente da concentração $5 \%$, que sempre apresentou atividade relativamente alta nesses tempos de amostragem, com incremento de 
$37,45 \%$ no tempo 36 horas, $67,31 \%$ no tempo 72 horas, $67,65 \%$ no tempo 120 horas, $22,22 \%$ no tempo 216 horas e $42,91 \%$ no tempo 264 horas após o tratamento, todos comparados ao controle.

Segundo Bonaldo et al. (4), quando a planta reconhece uma molécula eliciadora rapidamente, ela consegue se proteger do patógeno com maior eficiência. Porém, neste estudo o aumento da atividade de polifenoloxidase começou mesmo depois do tratamento, tendo este aumento sido acentuado após a inoculação do patógeno, portanto, o rápido reconhecimento é que pode ter contribuído para os aumentos da atividade dessa enzima. O aumento constante e precoce pode ser negativo para a planta, pois mesmo conseguindo retardar o processo infeccioso ou mesmo impedi-lo, em alguns casos o gasto metabólico envolvido faz com que a indução não seja vantajosa, já que a planta precisaria de muita energia, e talvez essa energia seria equivalente àquela gasta na presença do patógeno, não sendo, portanto, uma boa alternativa.

Comparando-se o resultado das enzimas peroxidase e polifenoloxidase, nesta não ocorreu um priming com posterior evento secundário após o processo infeccioso. Porém, teve-se um incremento de indução no tratamento $5 \%$, que se manteve durante todo o período de amostragem. Isto não seria interessante em termos de controle da doença, porque mesmo na ausência da infecção nos tempos 36 e 72 horas após o tratamento a atividade continuou alta, o que gera um elevado custo metabólico para a planta.

Em trabalho realizado por Silva et al. (23) utilizando Bacillus cereus, foi verificada alta atividade de peroxidase, sendo este aumento 10 vezes superior à atividade normal desta enzima. Isso demostra que dependendo da interação podem-se observar resultados completamente distintos, assim como o encontrado neste trabalho comparando a atividade de peroxidase e de polifenoloxidase para o mesmo patossistema.

Quanto a produção de polifenoloxidase no colo, ocorreu uma elevação na atividade a partir da aplicação do tratamento, diferentemente do que ocorreu com a atividade desta enzima na raiz, onde se observou um pico inicial de incremento na atividade, com posterior volta a atividade normal e, depois, um novo pico de atividade após a inoculação do patógeno. Segundo Agrios (1), a atividade de polifenoloxidase, na grande maioria dos casos, apresenta níveis mais elevados nos tecidos infectados. Isso poderia justificar o aumento da atividade desta enzima no colo, visto que nesta região foi realizada a inoculação do patógeno e possivelmente tenha sido o local de início e maior ação por parte do patógeno.

Em relação a atividade de fenilalanina amônia-liase (FAL) tratadas com extrato de alecrim no colo (Figura 1C), a única concentração que promoveu incremento significativo na atividade desta enzima foi $5 \%$, sendo este incremento $82,84 \%$ maior que o controle no tempo 168 horas e $130,09 \%$ maior no tempo 216 horas após o tratamento.

Estes resultados demostram que o extrato de alecrim para a atividade da enzima FAL atuou de maneira diferente que para a atividade da enzima peroxidase, pois não foi verificado para FAL o comportamento de priming, ou seja, não houve dois eventos de indução e sim apenas um pico que ocorreu depois da inoculação do patógeno. Este incremento foi devido à colonização do patógeno e também devido a indução do tratamento na concentração $5 \%$ de extrato de alecrim, pois não foi verificado incremento na atividade nas demais concentrações testadas e nem no controle.

Resultados semelhantes foram encontrados por Kuhn (13) em feijoeiros tratados com Bacillus cereus na concentração $10^{8}$ ufc $\mathrm{mL}^{-1}$ e ASM na concentração de $50 \mathrm{mg}$ i.a. $\mathrm{L}^{-1}$ do produto Bion ${ }^{\circledR}$, e, de acordo com o autor, isto pode ter significado que toda a rota dos fenilpropanóides não sofreu alterações.

Para o tratamento alecrim 5\%, o incremento da atividade da enzima peroxidase para a raiz (Figura 1D) ocorreu da mesma forma que no colo, ou seja, com a ocorrência de dois picos, um devido ao próprio tratamento 36 horas após este, com incremento de $60 \%$ e um segundo pico, cerca de $140 \%$ maior em relação ao controle. Este incremento pode ter ocorrido devido ao processo de indução, já que os demais tratamentos também foram inoculados.

Ao comparar a atividade de peroxidase para o colo e para a raiz observa-se que o segundo pico de indução ocorreu mais tarde nas amostras de raiz se comparada às amostras de colo. Isso pode ter ocorrido porque os tratamentos, no caso das raízes, foram administrados no solo e, no caso do colo da planta, foram aplicados diretamente na haste, assim, estas amostras tratadas diretamente sobre a área a ser amostrada podem ter sido beneficiadas com o incremento dos resultados e de uma resposta mais rápida.

Foi observado também um pico de atividade dessa enzima no tempo 120 horas após o tratamento, quando utilizado alecrim na concentração. Nas amostras de colo, a concentração $2,5 \%$ apresentou dois picos de incremento na atividade, porém, na raiz, apenas um pico foi verificado no tempo 120 horas após o tratamento, em que o incremento foi de $83 \%$ se comparado ao controle.

Sabendo que as peroxidases atuam eliminando certos átomos de hidrogênio de grupos álcoois hidroxicinâmicos, os quais formam a lignina, e que somada a celulose e outros polissacarídeos atuam como barreira física para dificultar a penetração do patógeno (6), sua elevada atividade pode contribuir para dificultar o estabelecimento da doença já que influencia na entrada do patógeno.

Para a atividade da enzima polifenoloxidase em raízes de soja (Figura 1E), observou-se que 36 horas após o tratamento, assim como ocorreu para a atividade dessa enzima no colo, houve o primeiro pico de atividade com o tratamento alecrim na concentração de $5 \%$ que diferiu do controle com valor cerca de $195 \%$ maior. A atividade nos tempos 72, 120 e 168 horas após o tratamento manteve-se estável, não havendo diferença estatística quando comparados ao controle.

Assim como encontrado na atividade da enzima peroxidase no colo e na raiz, em relação à atividade da polifenoloxidase, o extrato de alecrim na concentração 5\% também demostrou dois picos de indução. O primeiro pico ocorreu 36 horas após o tratamento e pode estar relacionado com o próprio efeito indutor do tratamento ou até mesmo a um efeito priming, já que não havia sido realizada a inoculação e porque a atividade nos tempos 72, 120 e 168 horas após o tratamento tendeu a voltar ao normal, não diferindo do controle.

Após a inoculação do fungo (72 horas após o tratamento) e, levando em consideração que o processo infeccioso demora alguns dias para iniciar o processo infeccioso, verificou-se no tempo 216 horas após o tratamento a ocorrência do segundo pico, sendo este muito maior que o primeiro e demonstrando um incremento de $425,93 \%$ na atividade da enzima quando comparado ao controle. Este segundo pico pode estar relacionado não apenas ao processo infeccioso em si, mas principalmente, ao processo de indução de resistência, uma vez que os demais tratamentos e o controle também passaram pelo processo de inoculação e não tiveram atividade da polifenoloxidase incrementada.

O fato da concentração $5 \%$ do extrato de alecrim ter causado um aumento constante na atividade de polifenoloxidase no colo das plantas pode ter ocorrido porque o tratamento foi administrado diretamente sobre o tecido desta região. Infere-se que esta não é uma opção no controle de doenças da soja, pois gera um elevado custo metabólico, 
fazendo com que a planta gaste energia. Em condições de campo, caso em uma lavoura a doença não ocorra e as plantas fossem tratadas, haveria um gasto metabólico desnecessário que implicaria em menor produtividade.

Segundo Romeiro \& Garcia (22), quando uma planta é exposta a um determinado eliciador de forma antecipada, ou seja, preventiva, seus tecidos demostram reação mais rápida e eficiente do que durante as tentativas de colonização do patógeno. Segundo Romeiro \& Garcia (22) isto seria um estado primário de indução da planta, ou seja, uma sensibilização ou um condicionamento da mesma. $\mathrm{O}$ contato entre o eliciador e a planta de forma precoce desencadearia, portanto, a síntese de algumas substâncias as quais se comportariam como sinais bioquímicos, que podem dominar a planta, desencadeando um processo de indução, como observado neste trabalho com a peroxidase no colo e nas raízes e com a polifenoloxidase nas raízes, onde há um primeiro pico de indução e, posteriormente, picos que compreendem maior atividade tanto por indução quanto pela colonização do patógeno, sendo estes mais significativos que os primeiros.

Quanto à atividade de FAL na raiz (Figura $1 \mathrm{~F}$ ) das plantas de soja tratadas com extrato de alecrim, assim como no colo, a concentração $5 \%$ foi a única que promoveu incremento significativo na atividade desta enzima, sendo este aumento de $340,58 \%$ no tempo 216 horas após o tratamento. Para a atividade de FAL no colo, observou-se que esta aconteceu mais cedo quando comparada a raiz, e se manteve por dois tempos de amostragem (168 e 216 horas após o tratamento), diferentemente das amostras de raiz onde o incremento ocorreu apenas 216 horas após o tratamento, porém, o acréscimo foi superior ao do colo.

Provavelmente, a antecipação da indução ocorrida nas amostras de colo é devido ao fato de os tratamentos terem sido aplicados no colo e no solo, assim, no caso das amostras de colo, o tratamento foi diretamente sobre o colo, e no caso das amostras de raiz, os tratamentos foram no solo e entraram em contato com a raiz conforme se aproximavam delas.

Este pico da atividade da enzima deve estar relacionado ao processo infeccioso e também ao processo de indução da resistência, já que a atividade foi verificada apenas para a concentração $5 \%$ de extrato de alecrim, não sendo verificada nem para as demais concentrações nem para o controle, sendo que também foram plantas inoculadas. Se essa indução fosse apenas relacionada à inoculação ou avanço da infecção, geraria também esse incremento nas plantas tratadas com água, o que não ocorreu.

Segundo Klessig \& Malamy (12), a atividade da enzima FAL produz precursores para a biossíntese de lignina e de outros compostos fenólicos, os quais se depositam como reação a infecção. Neste estudo, tanto para as amostras de colo quanto para as amostras de raiz não foi observado um pico de indução inicial assim como ocorreu para outras enzimas testadas, porém, observou-se que houve um pico de atividade dessa enzima após a inoculação, o qual não estaria relacionado apenas com o processo de colonização do patógeno, mas também ao indutor, ou seja, seria uma atividade elevada devido a indução pelo extrato de alecrim $5 \%$, visto que o mesmo não foi observado para os demais tratamentos ou para o controle, os quais também passaram pelo processo de indução.

O extrato de alecrim foi capaz de induzir a atividade de peroxidase, polifenoloxidase e fenilalanina amônia-liase em colo e raiz de plantas de soja desafiadas com M. phaseolina, revelando a ação de eliciadores presentes neste extrato com efeito dose-dependente para a ativação desses mecanismos.

\section{REFERÊNCIAS}

1.Agrios, G.N. Plant Pathology. 5th ed. San Diego: Elsevier, 2005. p.207-248. 2.Almeida, A.M.R.; Seixas, C.D.S.; Farias, J.R.B.; Oliveira, M.C.N; Franchini, J.C.; Debiasi, H.; Costa, J.M.; Gaudêncio, C.A. Macrophomina phaseolina em soja. Londrina: Embrapa Soja, 2014. 55p.

3.Boava, L.P.; Kuhn, O.J.; Pascholati, S.F.; Di Piero, R.M.; Furtado, E.L. Efeito de indutores bióticos e abióticos na atividade de quitinase e peroxidase e no controle da ferrugem causada por Puccinia psidii em eucalipto. Summa Phytopathologica, Botucatu, v.36, n.2, p.168-172, 2010.

4.Bonaldo, S.M.; Pascholati, S.F; Romeiro, R.S. Indução de resistência em plantas a patógenos e insetos. Piracicaba: FEALQ, 2005. p.11-28.

5.Bradford, M.M. A rapid and sensitive method for the quantitation of microgram quantities of protein utilizing the principle of protein-dye binding. Analytical Biochemistry, New York, v.72, p.248-254, 1976.

6.Cavalcanti, L.S.; Brunelli, K.R.; Stangarlin, J.R. Aspectos bioquímicos e moleculares da resistência induzida. In: Cavalcanti, L.S.; Di Piero, R.M.; Cia, P.; Pascholati, S.F.; Resende, M.L.V.; Romeiro, R.S. (Ed.). Indução de resistência em plantas a patógenos e insetos. Piracicaba: FEALQ, 2005. p.81-124.

7.Cruz, C.D. Genes: a software package for analysis in experimental statistics and quantitative genetics. Acta Scientiarum. Agronomy, Maringá, v.35, n.3, p.271-276, 2013.

8.Duangmal, K.; Apenten, R.K.O. A comparative study of polyphenoloxidases from taro (Colocasia esculenta) and potato (Solanum tuberosum var. Rof man). Food Chemistry, London, v.64, p.351-359, 1999.

9.Formentini, H.M. Avaliação de indutores de resistência biótico, abiótico e extratos vegetais no controle de Meloidogyne incognita em tomateiro. 2012. 59f. Tese (Doutorado em Agronomia)-Universidade Estadual do Oeste do Paraná, Marechal Cândido Rondon.

10.Hammerschimidt, T.R.; Nucles, E.M.; Kuc, J. Association of enhanced peroxidase activity with induced systemic resistance of cucumber to Colletotrichum lagenarium. Physiological Plant Pathology, Berlin, v.20, p.73-82, 1982.

11.Itako, A.T.; Schwan-Estrada, K.R.F.; Stangarlin, J.R.; Tolentino Júnior, J.B.; Cruz, M.E.S. Controle de Cladosporium fulvum em tomateiro por extratos de plantas medicinais. Arquivos do Instituto Biológico, São Paulo, v.76, p.7583, 2009.

12.Klessig, D.F.; Malamy, J. The salicylic acid signal in plants. Plant Molecular Biology, Zurich, v.26, p.1439-1458, 1994.

13.Kuhn, O.J. Indução de resistência em feijoeiro (Phaseolus vulgaris) por acibenzolar-S-metil e Bacillus cereus: aspectos fisiológicos, bioquímicos e parâmetros de crescimento e produção. 2007. 140f. Tese (Doutorado em Agronomia)-Escola Superior de Agricultura "Luiz de Queiroz", Universidade de São Paulo, Piracicaba.

14.Maia, A.J.; SchwanEstrada, K.R.F; Faria, C.M.D.R.; Oliveira, J.S.B.; Jardinetti, V.A.; Batista, B.N. Óleo essencial de alecrim no controle de doenças e na indução de resistência em videira. Pesquisa Agropecuária Brasileira, Brasília, DF, v.49, n.5, p.330-339, 2014

15.Martins, E.S.C.S.; Farias, M.A.A.; Santos, M.S.; Barros, H.M.M. Efeito dos óleos essenciais de citronela, alecrim e erva-cidreira no controle in vitro de Ralstonia solanacearum em pimentão. Tecnologia e Ciência Agropecuária, João Pessoa, v.4, n.1, p.9-13, 2010.

16.Mattei, D.; Dias-Arieira, C.R.; Biela, F.; Roldi, M.; Silva, T.R.B.; Rampim, L.; Dadazio, T.S.; Tavares-Silva, C.A. Essential oil of Rosmarinus officinalis in the control of Meloidogyne javanica and Pratylenchus brachyurus in soybean. Bioscience Journal, Uberlândia, v.30, n.2, p.469-476, 2014.

17.Menezes, V.O.; Pedroso, D.C.; Dill, A.M.; Santos, R.F.; Muller, J.; Junges, E.; Muniz, M.; Blume, E. Uso de extratos vegetais in vivo no controle de Alternaria solani e na produtividade do tomateiro. Revista Brasileira de Agroecologia, Cruz Alta, v.4, n.2, p.1108-1112, 2009.

18.Mengistu, A.; Arelli, P.A.; Bond, J.P.; Shannon, G.J.; Wrather, A.J.; Rupe, J.B.; Chen, P.; Little, C.R.; Canaday, C.H.; Newman, M.A.; Pantalone, V.R. Evaluation of soybean genotypes for resistance to charcoal rot. Plant Management Network, Saint Paul, v. , n. , p.1-15, 2011. Disponível em: $<$ https://www.plantmanagementnetwork.org/pub/php/research/2011/charcoal/>. Acesso em: $21 \mathrm{dez} .2016$.

19.Müller, M.A.; Mioranza, T.M.; Stangarlin, J.R.; Kuhn, O.J.; Battistus, A.G.; Istchuk, A.N.; Fuchs, F. In vitro toxicity and control of Meloidogyne incognita in soybean by rosemary extract. Semina: Ciências Agrárias, Londrina, 
v.37, p.103-110, 2016.

20.Portz, R.L.; Koehl, J.; Fleischmann, F.; Osswald, W. Histological, physiological and molecular investigations of Fagus sylvatica seedlings infected with Phytophthora citricola. Forest Pathology, Medford, v.41, p.202-211, 2011

21.Resende, M.L.V.; Barreti, P.B.; Medeiros, F.C.L.; Silva, D.D.; Pereira, R.B.; Lins, S.R.O.; Pereira, L.M.; Campos, M.A. Percepção e transdução de sinais para a ativação de respostas de defesa em plantas contra patógenos. Revisão Anual de Patologia de Plantas, Passo Fundo, v.15, p.173-242, 2007.

22.Romeiro, R.S.; Garcia, F.A.O. Indução de resistência em plantas a patógenos por eliciadores de natureza bacteriana. In: Bettiol, W.; Morandi, M.A.B. Biocontrole de doenças de plantas: uso e perspectivas. Jaguariúna: Eme brapa Meio Ambiente, 2009. cap.6, p.85-100.

23.Silva, H.S.A.; Romeiro, R.S.; Macagnan, D.; Halfeld-Vieira, B.A.; Pereira, M.C.B.; Mounteer, A. Rhizobacterial induction of systemic resistance in tomato plants: non-specific protection and increase in enzyme activities. Biological Control, Orlando, v.29, p.288-295, 2003.
24.Stangarlin, J.R.; Kuhn, O.J.; Toledo, M.V.; Portz, R.L.; Schwan-Estrada, K.R.F.; Pascholati, S.F. A defesa vegetal contra fitopatógenos. Scientia Agraria Paranaensis, Marechal Candido Rondon, v.10, p.18-46, 2011.

25.Stangarlin, J.R.; Kuhn, O.J.; ASSI, L.; Schwan-Estrada, K.R.F. Control of plant diseases using extracts from medicinal plants and fungi. In: Méndez-Vilas, A. (Ed.). Science against microbial pathogens: communicating current research and technological advances. Badajoz: Formatex, 2011. p.1033-1042.

26.Teske, M.; Trentini, A.M.M. Herbarium: compêndio de fitoterapia. 3.ed. Curitiba: Herbarium Laboratório Botânico, 1997. 317p.

27.Umesha, S. Phenylalanine ammonia lyase activity in tomato seedlings and its relationship to bacterial canker disease resistance. Phytoparasitica, Rehovot, v.34, n.1, p.68-71, 2006.

28.Viecelli, C.A.; Stangarlin, J.R.; Kuhn, O.J.; Schwan-Estrada, K.R.F. Indução de resistência em feijoeiro a mancha angular por extratos de micélio de Pycnoporus sanguineus. Summa Phytopathologica, Botucatu, v.36, n.1, p. 73-80, 2010. 